\title{
Divergence of Phyllosphere Microbial Communities Between Females and Males of the Dioecious Populus cathayana
}

\author{
Liling Liu, ${ }^{1,2}$ Lu Lu, ${ }^{1,3,+}$ Huilin Li, ${ }^{1}$ Zhensi Meng, ${ }^{1}$ Tingfa Dong, ${ }^{1}$ Chao Peng, ${ }^{1,4}$ and Xiao Xu ${ }^{1,2, \dagger}$ \\ ${ }^{1}$ Key Laboratory of Southwest China Wildlife Resources Conservation, College of Life Sciences, China West Normal University, \\ Nanchong 637002, China \\ ${ }^{2}$ Institute of Ecology, China West Normal University, Nanchong 637009, China \\ ${ }^{3}$ College of Environmental Science and Engineering, China West Normal University, Nanchong 637009, China \\ ${ }^{4}$ Chemical Synthesis and Pollution Control Key Laboratory of Sichuan Province, College of Chemistry and Chemical \\ Engineering, China West Normal University, Nanchong 637002, China
}

Accepted 7 December 2020.

Females and males of dioecious plants have evolved sex-specific characteristics in terms of their morphological and physiological properties. However, the differentiation of phyllosphere microbiota in dioecious plants remains largely unexplored. Here, the diversity and composition of female and male Populus cathayana phyllosphere bacterial and fungal communities were investigated using 16S rRNA/ITS1 gene-based MiSeq sequencing. The divergences of bacterial and fungal community compositions occurred between females and males. Both females and males had their unique phyllosphere bacterial and fungal microbiota, such as bacterial Gemmata spp. (5.41\%) and fungal Pringsheimia spp. $(0.03 \%)$ in females and bacterial Chitinophaga spp. $(0.009 \%)$ and fungal Phaeococcomyces spp. (0.02\%) in males. Significant differences in the relative abundance of phyla Proteobacteria and Planctomycetes bacteria and phyla Ascomycota and Basidiomycota fungi $(P<0.05)$ were also found between females and males. Some bacterial species of genera Spirosoma and Amnibacterium and fungal genera Venturia, Suillus, and Elmerina spp. were significantly enriched in males $(P<0.05)$. In contrast, levels of fungal genera Phoma and Aureobasidium spp. were significantly higher in females than in males $(P<0.05)$. The mineral,

Liling Liu and Lu Lu contributed equally to this work.

The nucleotide sequences of bacteria and fungi are deposited in GenBank under accession numbers SRR8237405 to SRR8237420 and SRR8237275 to SRR8237290, respectively.

${ }^{\dagger}$ Corresponding authors: L. Lu; 1lu327@cwnu.edu.cn and

X.Xu; xuxiao_cwnu@163.com

Funding: This work was financially supported by the National Natural Science Foundation of China (31370596 and 41606142), the Innovative Team Foundation of the Sichuan Provincial Department of Education (14TD0015) and the Innovative Team Foundation of China West Normal University (CXTD2020-2).

*The $\boldsymbol{e}$-Xtra logo stands for "electronic extra" and indicates there is supplementary material published online.

The author(s) declare no conflict of interest.

Copyright (C) 2021 The Author(s). This is an open access article distributed under the CC BY 4.0 International license. inorganic, and organic nutrients content contributed differently to the divergence of female and male phyllosphere microbial communities, with 87.08 and $45.17 \%$ of the variations being explained for bacterial and fungal communities, respectively. These results highlight the sexual discrimination of phyllosphere microbes on the dioecious plants and provide hints on the potential host-associated species in phyllosphere environments.

Keywords: dioecious plants, microbial community, MiSeq sequencing, phyllosphere, Populus cathayana

Dioecious plants consist of more than 14,620 angiosperm species (Renner and Ricklefs 1995). Among these species, Populus cathayana is extensively distributed in temperate zone. As a common afforestation species, $P$. cathayana are fastgrowing trees with the characteristic of strong adaptability, easy reproduction, and wide application, and it is widely used in ecological management, environmental improvement, and wood processing (Xu 2008). Recently, the differences between female and male plants have become a topic of considerable interest. The sexual differences in morphology, resource allocation, and reproductive allocation, stress adaptive capacity, and nutrient availability in stressful environments have been extensively addressed (Cipollini and Whigham 1994; Leigh et al. 2006; Wu et al. 2018; Zhang et al. 2010a, 2014b). Female and male $P$. cathayana have been found to differ in leaf morphology (Zhang et al. 2011), $\mathrm{N}$ use efficiency (Zhao et al. 2009), leaf senescence speed (Chen et al. 2010), total leaf area per unit of stem mass (Yang et al. 2015), and net photosynthesis rate (Xu et al. 2008b). Zhao et al. (2011) also found that the chlorophyll $\mathrm{a} / \mathrm{b}$ content in male $P$. cathayana was higher than that in females. Male $P$. cathayana possess a more-efficient antioxidant system, a higher anthocyanin content to alleviate UV-B radiation, and a better self-protection mechanism than females (Xu et al. 2008a and b, 2010; Zhang et al. 2010a, 2012). Moreover, whether the morphological and physicochemical differences drive the divergence of phyllosphere bacterial and fungal communities in male and female $P$. cathayana, particularly in complex natural forests, is still unclear.

The phyllosphere, comprising the aerial surfaces of terrestrial plants, is considered the largest biological interface on Earth (Bailey et al. 2006). Reports conservatively estimate that the 
global leaf surface is approximately $6.4 \times 10^{8}$ per square kilometer in area and harbors more than $10^{26}$ microorganisms (Leveau and Lindow 2001; Lindow and Brandl 2003; Vorholt 2012). Although exposed to highly variable environmental factors, including UV radiation, temperature, water availability humidity, and heterogeneous nutrient availability (Lindow and Leveau 2002; Rastogi et al. 2013), the leaf surface is still colonized by highly diverse microorganisms, such as bacteria, fungi, and archaea, which are called phyllosphere microbes (Lindow and Brandl 2003). Phyllosphere microbiota were found to be in symbiosis with hosts and influence growth and ecological function in many ways, such as increasing plants stress tolerance (Delmotte et al. 2009; Kaczmarczyk et al. 2011), production of growth-promoting nutrients and hormones of plants (Bulgarelli et al. 2013; Fürnkranz et al. 2008; Reed et al. 2010), and protection of hosts against pathogen (Balint-Kurti et al. 2010; Innerebner et al. 2011). For dioecious plants, previous studies have shown that there are significant sexual differences in the physiological responses of $P$. cathayana under stressful conditions, such as nutritional deficiencies, drought, light, and temperature (Xu et al. 2008b; Zhang et al. 2014b; Zhao et al. 2009). These studies underscore the possibility of the differentiation of phyllosphere microbiota in P. cathayana. Additionally, the diversity of phyllosphere microbial communities is closely related to the physicochemical properties of leaves. For example, previous studies showed that different leaf-surface features, such as stomata, hydathodes, water, and phosphorus contents, and mesophyll thickness resulted in an uneven microorganism distribution on leaf surfaces (Kembel and Mueller 2014; Mariano and McCarter 1993; Mew 1984; Yadav et al. 2005). Hunter et al. (2010) revealed that plant morphology and soluble carbohydrate content also significantly influenced the diversity of the phyllosphere bacterial community. In addition, recent studies have reported that plant genotype is a critical factor influencing the microbial composition of the phyllosphere microorganisms (Redford and Fierer 2009; Whipps et al. 2008). However, most of the current studies on phyllosphere microorganisms are on crops and monoecious plants, and systematic comparisons of the phyllosphere bacterial and fungal communities of dioecious plants are still lacking.

In this study, the common native dioecious species P. cathayana Rehd, in the Xiaowutai Mountain Nature Reserve, Hebei Province, China, was chosen to characterize and compare the diversity and composition of the female and male phyllosphere bacterial and fungal communities using $16 \mathrm{~S}$ rRNA/ITS1 gene-based MiSeq sequencing. Previous studies revealed that the definition of endophytic and epiphytic microorganisms was ambiguous and some epiphytic fungi can penetrate into the epidermis or stomata and colonize internal leaf tissues (Cordier et al. 2012a; Viret and Petrini 1994). The sequenced phyllosphere microbial communities comprise both

Table 1. The physicochemical characteristics of leaves ${ }^{\mathrm{z}}$

\begin{tabular}{lcc}
\hline Leaf physicochemical properties & Female & Male \\
\hline $\mathrm{pH}$ & $5.97 \pm 0.15 \mathrm{a}$ & $5.83 \pm 0.13 \mathrm{a}$ \\
Moisture content $(\%)$ & $66.11 \pm 1.03 \mathrm{a}$ & $64.62 \pm 2.60 \mathrm{a}$ \\
$\mathrm{TC}(\mathrm{mg} / \mathrm{g})$ & $428.23 \pm 4.68 \mathrm{~b}$ & $454.98 \pm 6.27 \mathrm{a}$ \\
$\mathrm{TN}(\mathrm{mg} / \mathrm{g})$ & $15.06 \pm 3.56 \mathrm{a}$ & $18.33 \pm 6.37 \mathrm{a}$ \\
$\mathrm{TP}(\mathrm{mg} / \mathrm{g})$ & $1.04 \pm 0.26 \mathrm{a}$ & $1.13 \pm 0.41 \mathrm{a}$ \\
Starch $(\mathrm{mg} / \mathrm{g})$ & $87.03 \pm 17.70 \mathrm{a}$ & $120.46 \pm 33.20 \mathrm{a}$ \\
Soluble sugar (mg/g) & $79.37 \pm 20.77 \mathrm{a}$ & $69.61 \pm 14.24 \mathrm{a}$ \\
$\mathrm{K}(\mathrm{mg} / \mathrm{g})$ & $11.83 \pm 4.52 \mathrm{a}$ & $8.70 \pm 2.14 \mathrm{a}$ \\
$\mathrm{Ca}(\mathrm{mg} / \mathrm{g})$ & $25.72 \pm 2.68 \mathrm{a}$ & $25.21 \pm 2.51 \mathrm{a}$ \\
$\mathrm{Mg}(\mathrm{mg} / \mathrm{g})$ & $2.60 \pm 0.41 \mathrm{a}$ & $2.37 \pm 0.45 \mathrm{a}$ \\
$\mathrm{Fe}(\mathrm{mg} / \mathrm{g})$ & $0.58 \pm 0.14 \mathrm{a}$ & $0.49 \pm 0.17 \mathrm{a}$ \\
$\mathrm{Cu}(\mathrm{mg} / \mathrm{kg})$ & $7.97 \pm 0.80 \mathrm{a}$ & $6.98 \pm 0.73 \mathrm{a}$ \\
\hline $\mathrm{Diffent}$
\end{tabular}

${ }^{\mathrm{z}}$ Different letters following values within the same lines indicate significant differences between females and males $(P<0.05)$. the surface and the interior of leaves (Delmotte et al. 2009; Jumpponen and Jones 2009). This work addressed two key questions. i) Are there sex-specific variation in the phyllosphere bacterial and fungal communities between females and males, and ii) do physicochemical properties of leaves contribute to the divergence of bacterial and fungal communities between females and males. Our results could provide insights into the genetic resources that are host-associated in dioecious plants.

\section{RESULTS}

\section{Sexual differences in leaf physicochemical properties.}

The 12 physicochemical characteristics of female and male leaf samples were shown in Table 1. The total carbon (TC) content in male leaves was significantly higher than that in female leaves $(P<0.001)$, with concentrations of 454.98 and $428.23 \mathrm{mg} / \mathrm{g}$, respectively. There was no significant difference in $\mathrm{pH}$, moisture content, total nitrogen (TN), total phosphorus (TP), starch, soluble sugar contents, and mineral content $(\mathrm{K}$, $\mathrm{Ca}, \mathrm{Mg}, \mathrm{Cu}$, and $\mathrm{Fe})$ between female and male leaves $(P>$ $0.05)$.

\section{Sexual differences in richness and diversity of phyllosphere microbial communities.}

In total, 894,616 and 779,162 high-quality bacterial and fungal sequences were obtained from eight female leaf samples and eight male leaf samples (Supplementary Table S1). The rarefaction analyses indicated that the diversity of all samples was well-represented by the number of sequences analyzed (Supplementary Fig. S1). The bacterial sequences in the female and male phyllosphere microbial communities were clustered into 510 and 584 operational taxonomic units (OTUs) at a $97 \%$ sequence similarity, respectively. The fungal sequences were clustered into 470 and 550 OTUs in females and males, respectively (Supplementary Table S1). Both females and males had their shared and unique bacteria and fungi OTUs (Supplementary Fig. S2). As to the alpha-diversity indexes, no significant differences between female and male phyllosphere bacterial and fungal communities were detected in the Chao1, abundance-based coverage estimator (ACE), Shannon, and Simpson indexes $(P>0.05)$ (Fig. 1A). Similarities of the phyllosphere bacterial and fungal communities between sexes were compared by non-metric multidimensional scaling (NMDS) and the adonis test based on Bray-Curtis. Stress values of $<0.2$ and $<0.1$ indicated good to potential useful interpretation and appropriate representativeness, respectively. NMDS analysis showed that phyllosphere bacterial and fungal communities of females and males were distributed in different quadrants (Fig. 1B). To verify the dominant role of sex selection on microbial communities, the variations between the individual samples and females vs. males were determined using principal component analysis and adonis test ( $P$ values) (Table 2; Supplementary Figs. S3 and S4). As shown in Table 2, the degree of variation inferred by the mean square values was greater between females and males (mean squares of 0.332 and 0.167 for bacterial and fungal communities, respectively) than among all individual samples (mean squares of 0.002 and 0.059 for bacterial and fungal communities, respectively). These results indicated that the interplant (females vs. males) variation was greater than that of intraplant (among individuals) in microbial communities.

\section{Sexual differences in the composition of the phyllosphere bacterial community.}

The dominant bacterial phyla were Proteobacteria, Bacteroidetes, Actinobacteria, Firmicutes, and Planctomycetes (Fig. 2A). The phylum Proteobacteria accounted for 91.46 and 
$95.48 \%$ of the total sequences in the female and male phyllosphere communities, respectively, and exhibited a significant difference in abundance between females and males based on the Metastats analysis $(P<0.05)$. The relative abundance of planctomycetes in females $(4.81 \%)$ was significantly higher than that in males $(1.77 \%)(P<0.05)$. The dominant bacterial classes were Alphaproteobacteria, Actinobacteria, Betaproteobacteria, and Cytophagia, representing 98.4 and $98.7 \%$ of the total sequences in females and males, respectively (Fig. 2C). Alphaproteobacteria was the most abundant class, accounting for 88.86 and $92.68 \%$ of the sequences both in females and males, respectively, showing no significant difference in abundance between them. At the genus level, nine bacterial genera were unique in the female phyllosphere, such as genus Gemmata $(5.41 \%)$, and some rare (relative abundance $<0.1 \%$ ), such as genera Rhodococcus, Brevundimonas, Devosia, Modestobacter, Xenophilus, and Vibrionimonas (Supplementary Fig. S5A). Two rare bacterial genera, Candidatus_Hodgkinia (0.03\%) and Chitinophaga (0.009\%), were unique in male phyllosphere (Fig. 3A). Moreover,

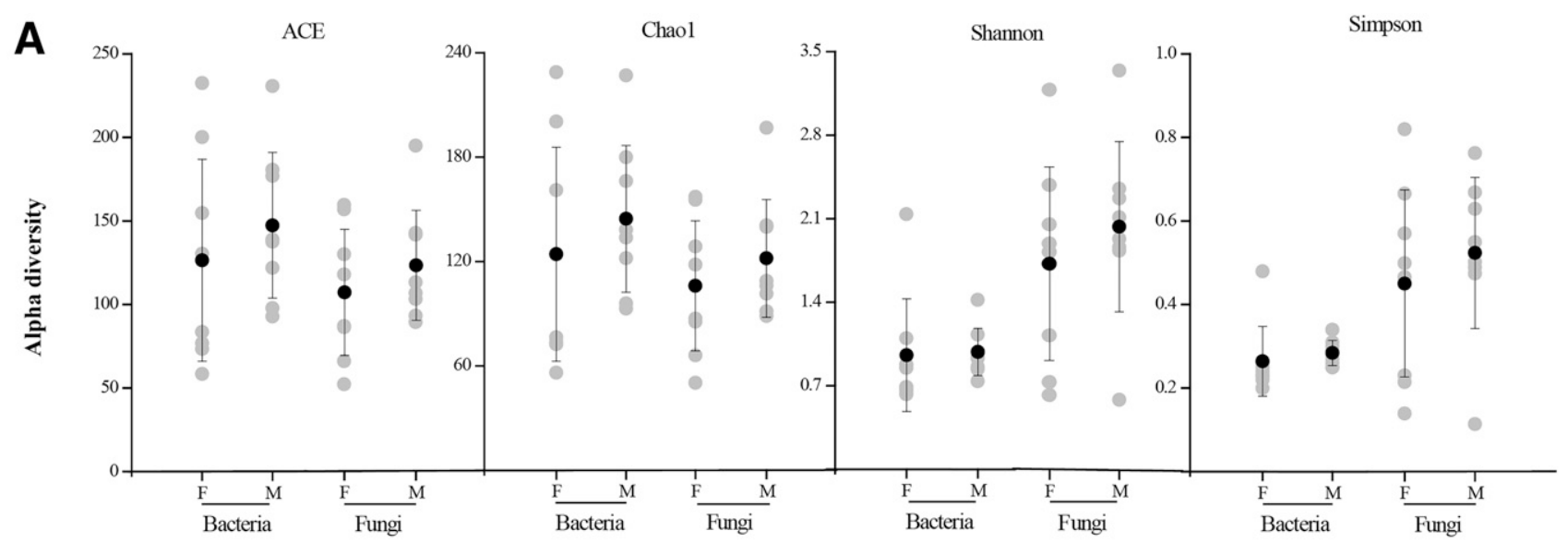

B
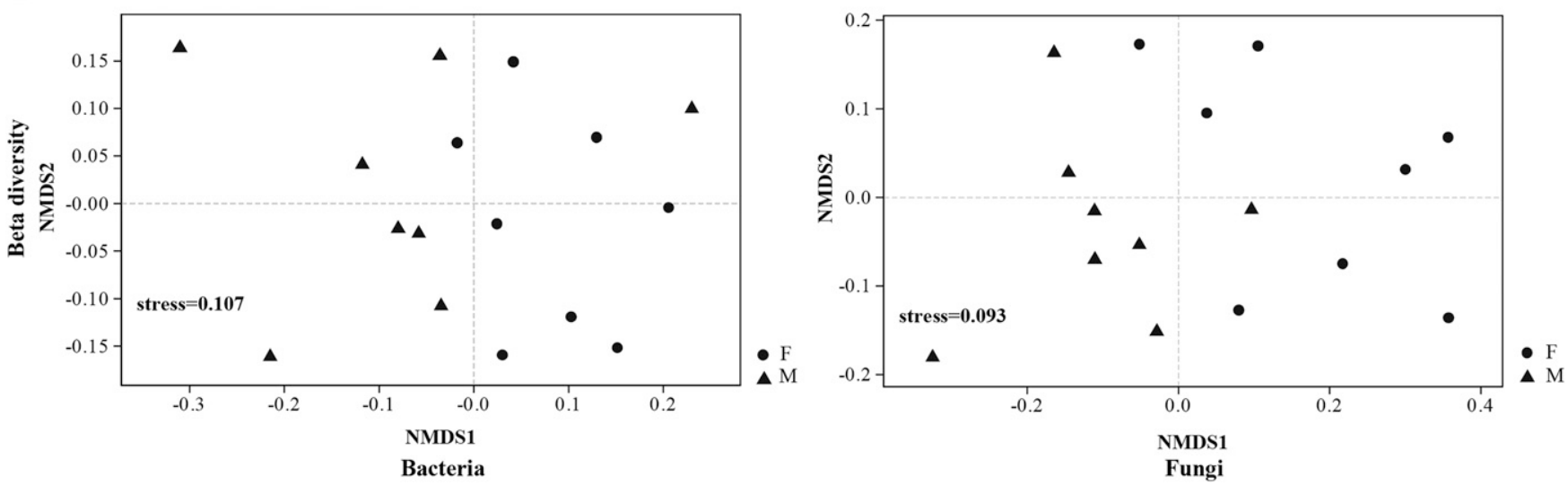

Fig. 1. A, Alpha diversity indexes of bacterial and fungal communities in the phyllosphere of female and male Populus cathayana. F and M represent female and male, respectively. Each group was conducted in eight repetitions. Error bars represent standard errors of the mean of the eight repetitions. B, Non-metric multidimensional scaling analysis, based on Bray-Curtis distance, showing microbial community composition differences between females and males.

Table 2. Permutational multivariate (adonis) analysis of variance of the phyllosphere bacterial and fungal composition between the individual samples and females versus males ${ }^{2}$

\begin{tabular}{|c|c|c|c|c|c|c|}
\hline Source & $d f$ & Sums of squares & Mean squares & $F$ & $R^{2}$ & $P$ \\
\hline \multicolumn{7}{|l|}{ Bacteria } \\
\hline \multicolumn{7}{|c|}{ Females vs. males (inter-variation) } \\
\hline Between sexes & 1 & 0.332 & 0.332 & 1.628 & 0.320 & 0.120 \\
\hline \multicolumn{7}{|c|}{ Among individuals (intra-variation) } \\
\hline Within females & 7 & 0.194 & 0.194 & 1.115 & 0.027 & 0.715 \\
\hline Within males & 7 & 0.144 & 0.144 & 1.031 & 0.031 & 0.532 \\
\hline All samples & 15 & 0.002 & 0.002 & 0.354 & 0.039 & 0.498 \\
\hline \multicolumn{7}{|l|}{ Fungi } \\
\hline \multicolumn{7}{|c|}{ Females vs. males (inter-variation) } \\
\hline Between sexes & 1 & 0.167 & 0.167 & 1.290 & 0.234 & 0.205 \\
\hline \multicolumn{7}{|c|}{ Among individuals (intra-variation) } \\
\hline Within females & 7 & 0.091 & 0.091 & 1.381 & 0.185 & 0.515 \\
\hline Within males & 7 & 0.020 & 0.020 & 0.563 & 0.022 & 0.836 \\
\hline All samples & 15 & 0.059 & 0.059 & 1.123 & 0.028 & 0.671 \\
\hline
\end{tabular}

\footnotetext{
${ }^{\mathrm{z}}$ The compositional dissimilarity between assemblages was assessed with the Bray-Curtis dissimilarity index.
} 
significantly higher relative abundances of the genera Spirosoma (male $1.38 \%$, female $0.32 \%$ ) and Amnibacterium (male $2.58 \%$, female $1.09 \%$ ) were observed in males than in females $(P<0.05)$ (Fig. 4A).

\section{Sexual differences in the composition of the phyllosphere fungal community.}

The dominant fungal phyla were Ascomycota, Basidiomycota, and Neocallimastigomycota, accounting for more than 99.83 and $99.91 \%$ of the fungal sequences in females and males, respectively (Fig. 2B). The relative abundance of Ascomycota was significantly higher in females than in males, whereas Basidiomycota showed the opposite trend $(P<0.05)$. Dothideomycetes and Leotiomycetes, belonging to the phylum Ascomycota, were the main classes in both females and males (Fig. 2D). The relative abundance of class Agaricomycetes in males was significantly higher than that in females $(P<0.05)$. With respect to the genus level, six fungal genera were unique in females (Fig. 3B), including genera Pringsheimia, Psathyrella, Farysizyma, and Sarocladium, with a relative abundance level of $<0.1 \%$. Ten fungal genera were only present in male phyllosphere. Among them, genus Phaeococcomyces (0.02\%) was the most dominant, and the relative abundances of other 9 genera were less than $0.01 \%$, such as genera Phaeococcomyces, Stachybotrys, and Tremella (Supplementary Fig. S5B). By comparing the relative abundance of shared genera, significantly higher relative abundances of genera Aureobasidium $(1.75 \%, P<0.05)$ and Phoma $(19.21 \%, P<0.001)$ were detected in females than in males. In contrast, significant higher relative abundances of genera Elmerina, Suillus, and Venturia were observed in males than in females $(P<0.05)$ (Fig. 4B).

\section{Multivariate correlation analysis between bacterial and} fungal communities and leaf physicochemical properties.

Variation partitioning analysis (VPA) based on partial redundancy analysis (RDA) illustrating the effects of environmental factors on the female and male phyllosphere microbial communities (Fig. 5; Supplementary Fig. S6; Supplementary Table S2). The VPA result showed that nonmetal parameters (including TC, TN, TP, soluble sugar, starch, and moisture content) were the most important contributors to the variance of bacterial communities between females and males, with $80.97 \%$ of the observed variation being explained. Mineral factors contributed $6.10 \%$ alone (Fig. 5A). As to the fungal
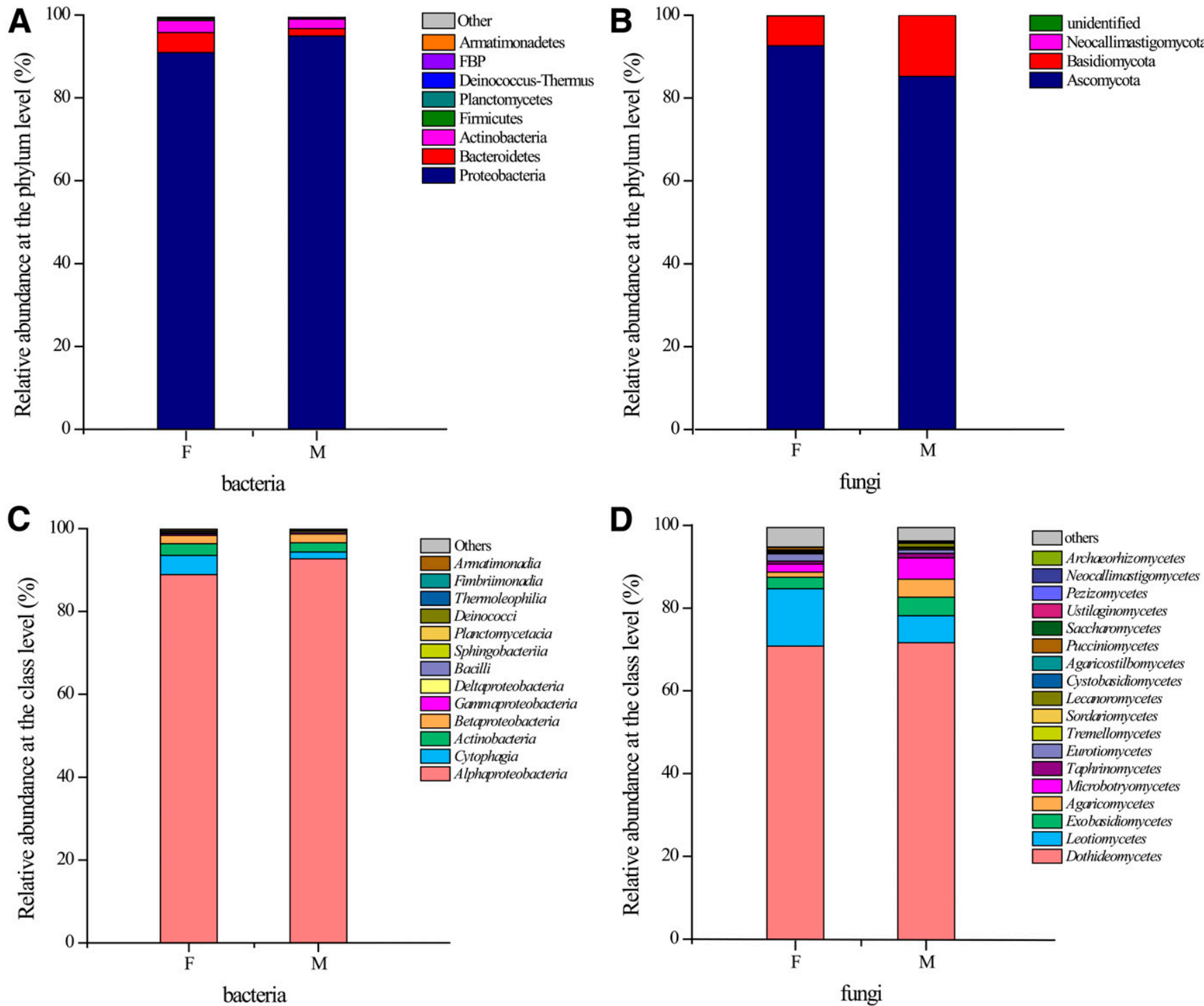

Fig. 2. A, Phylum-level taxonomic composition of the bacterial and B, fungal communities. C, Class-level taxonomic composition of the bacterial and $\mathbf{D}$, fungal communities. F and $\mathrm{M}$ represent female and male, respectively. 
communities, only $45.17 \%$ variation in fungal profiles of females and males was explained, and nonmetal parameters $(29.25 \%)$ were identified as the main driver for the differences in fungal communities of females and males. Metal contents contributed $5.92 \%$ of the total variance in fungal communities of females and males (Fig. 5B). Among these metals, Mg and Fe content contributed mostly to the variance with $3.45 \%$ of the total metal contribution (Supplementary Fig. S7). RDA results also showed that $\mathrm{Mg}$ and Fe content of leaves was the significant constraining variable shaping fungal community composition of the overall samples $(P<0.05)$ (Supplementary Fig. S6B).

\section{DISCUSSION}

In this study, no significant differences between the alpha diversity indexes of the female and male $P$. cathayana phyllosphere microbial communities was observed, whereas there were, indeed, some taxa discriminatingly inhabiting on females and males. The leaf physicochemical properties contributed differently to the differentiation of the microbial community compositions in females and males. The study could provide typical data for microbial sexual discrimination in dioecious plants and, thus, contribute to the increasing knowledge of microbial ecology in phyllosphere environment.

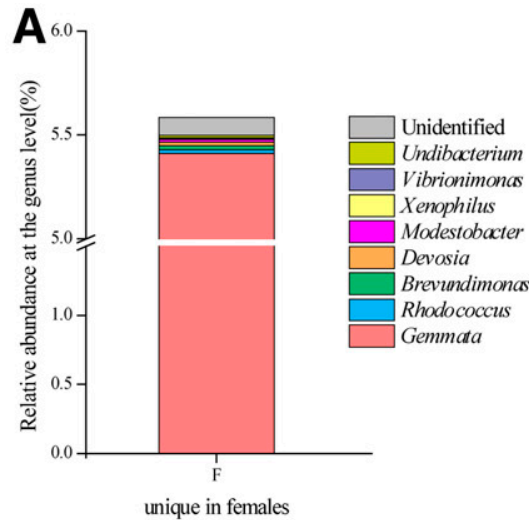

B

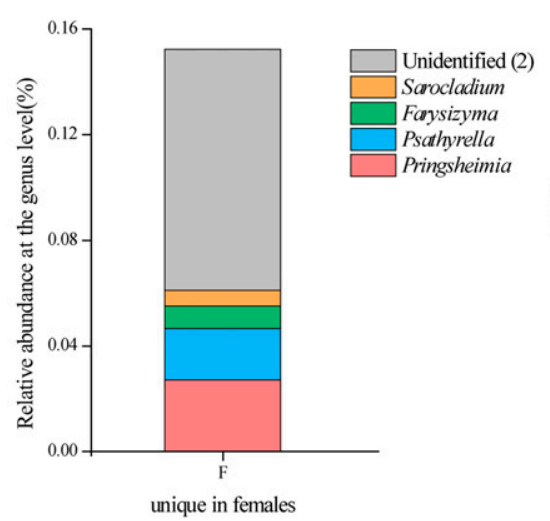

The number of genus

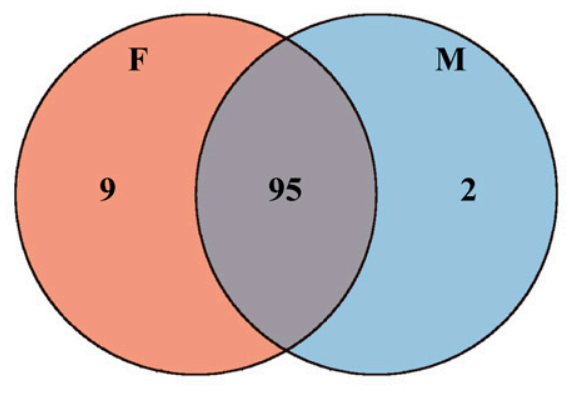

Bacteria

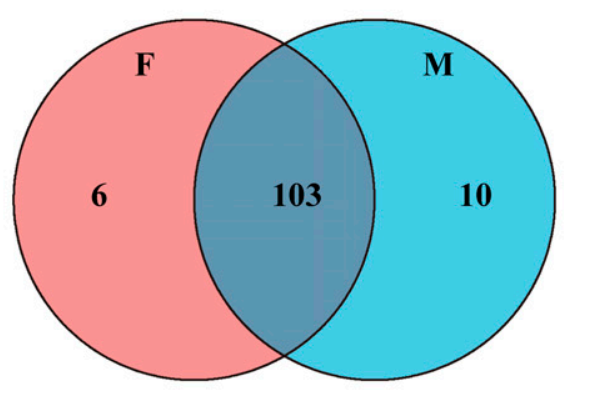

Fungi

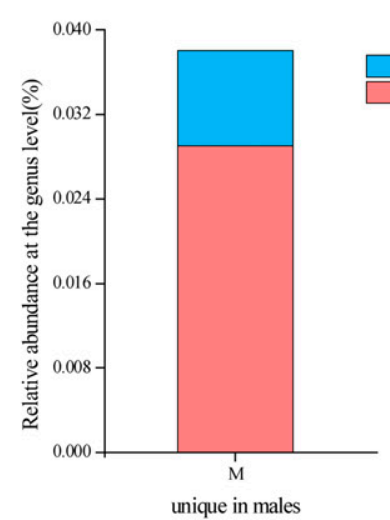

Chitinophaga Candidatus_Hodgkinia

Fig. 3. A, The shared and unique bacterial and B, fungal genera between female and male Populus cathayana. F and M represent female and male $P$. cathayana, respectively.
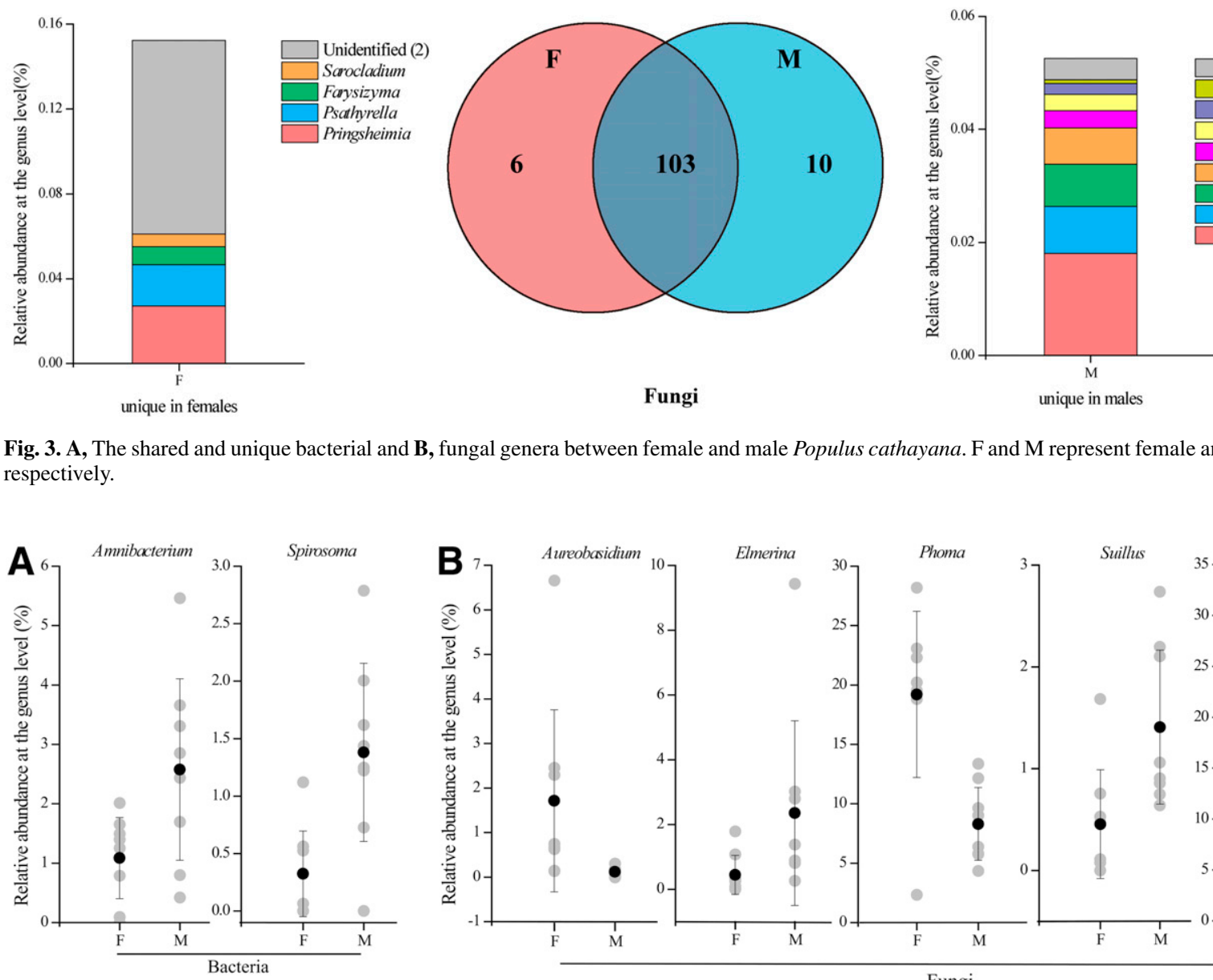

Unidentified (2) Udeniomyces Oxyporis Inocutis Hazia Inocybe Inocybe Tremella Stachybotrys

unique in males

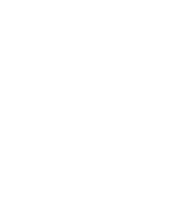


The TC content of the male leaves was higher than that in female leaves. The TC content of leaves is an indicator of plant carbon sequestration ability during photosynthesis (Boerner 1984), and photosynthesis is directly related to the availability of nutrients for microorganisms on the leaf surface and in the leaf tissues (Vacher et al. 2016). Compared with females, males exhibited a higher photosynthetic rate and carbon fixation rate (Xu et al. 2008a), which could explain the higher TC content in male leaves observed here. The other leaf properties measured here did not differ between the females and males, which was consistent with the results of previous studies on $P$. cathayana (Chen et al. 2014; Zhang et al. 2010a).

There were no significant differences in the alpha diversity indexes between females and males, which was consistent with the findings of a previous study showing that the phyllosphere microbial community structure of the same species showed little variability (Yang et al. 2001). Previous study had also shown that there was far more variability in phyllosphere microbial community structure across tree species than within species in the same habitat (Redford et al. 2010). The samples in this study were collected from the same hillside with similar elevation, temperature, rainfall, or solar, which might explain the undifferentiated diversity indexes between females and males. However, the differences in leaf-surface structure, element contents, stomatal distribution, gas exchange, and net photosynthetic rates (Liu 2003; Wang et al. 2010; Xu et al. 2008a) between females and males might lead to the divergence of the phyllosphere microbial communities (Yadav et al. 2005). The microbial OTU composition variation between female and male trees was much higher than that among individual trees, supporting the role of sex-selection on phyllosphere microbial communities (Table 2; Supplementary Figs. S3 and S4). As to the OTU result, the data showed that fungal species of most samples outstrip bacteria (Supplementary Table S1). This result is consistent with many previous studies (Kembel and Mueller 2014; Kembel et al. 2014). The OTU of each sample was 218 to 1,040, and 207 to 869 OTUs for bacterial and fungal communities were detected in all the samples at a $97 \%$ sequence similarity, which was much lower than the OTU number in soil or water samples (Chen et al. 2020; Wang et al. 2018). Many previous studies also found that only hundreds of OTUs were detected in phyllosphere microbial communities (Cordier et al. 2012a; Delmotte et al. 2009; Gomes et al. 2018; Kim et al. 2012; Ren et al. 2014).

An increasing body of studies has demonstrated the important roles of microbial communities in regulating the phyllosphere multifunctionality (Delmotte et al. 2009; Kembel et al. 2014; Stone et al. 2018). However, most of our knowledge is still based on dominant species or the diversity indexes, and less attention has been paid to some individual species or rare microbial taxa. Here, we identified both abundant and rare taxa that were enriched in females or males, respectively. For example, a significant higher proteobacteria relative abundance was observed in males than in females. The abundance of proteobacteria was often positively correlated with nutrient availability (Fierer 2017). The higher proteobacteria abundance in males was coupled well with higher leaf nutrition (TC, TN, $\mathrm{TP}$, and starch) in males (Table 1). In contrast, the higher relative abundance of planctomycetes in females might be explained by their potential capacity to resistance to chemical antimicrobial compounds (Wagner and Horn 2006). Previous studies have reported that contents of antimicrobial compounds were much higher in the phyllosphere of females than that of males (Cepeda-Cornejo and Dirzo 2010; Cornelissen and Stiling 2005). Thus, the planctomycetes could lose their competitive advantage over other bacterial groups in the phyllosphere of males (Bengtsson and Øvreås 2010), explaining their lower abundance in males. At the genus level, the higher abundance of Spirosoma spp. in males compared with females might be related to the higher UV-B resistance capacity of males (Xu et al. 2010). Many Spirosoma species revealed resistance to gamma and UV radiation, such as a Spirosoma radiotolerans (Lee et al. 2014) and Spirosoma swuense (Joo et al. 2017) (Supplementary Table S3). The ability to withstand UV radiation is thought to be an important adaptation for the survival of bacteria in the phyllosphere, and a previous study revealed that UV radiation can alter maize phyllosphere bacterial diversity (Kadivar and Stapleton 2003). Furthermore, the leaf area of males is generally larger than that of females (Cornelissen and Stiling 2005; Xu et al. 2010), so the leaves of males are exposed to more UV-B radiation compared with those of females. The higher abundance of Spirosoma spp. in males could be due to their high resistance to gamma and UV radiation (Lee et al. 2015). Genus Amnibacterium was found to be significantly enriched in males. The isolates Amnibacterium soli sp. and Amnibacterium kyonggiense, whose $16 \mathrm{~S}$ ribosomal RNA (rRNA) gene sequences were more than $97 \%$ similar with the Amnibacterium in males, can produce a wide range of biologically active metabolites, possess antibacterial activity, and promote the growth of plants by fixing nitrogen (Jiang et al. 2018; Selvakumar et al. 2014). The enrichment of Amnibacterium in males could contribute to the more effective pathogen defense mechanism in males compared with females (Zhang et al. 2010b). Besides, the unique genus Gemmata in females is related with sterol biosynthesis and has the ability to uptake proteins present in the external milieu through an energy-dependent and endocytosis-like process (Lonhienne et al. 2010; Pearson et al. 2003), such as its closely related

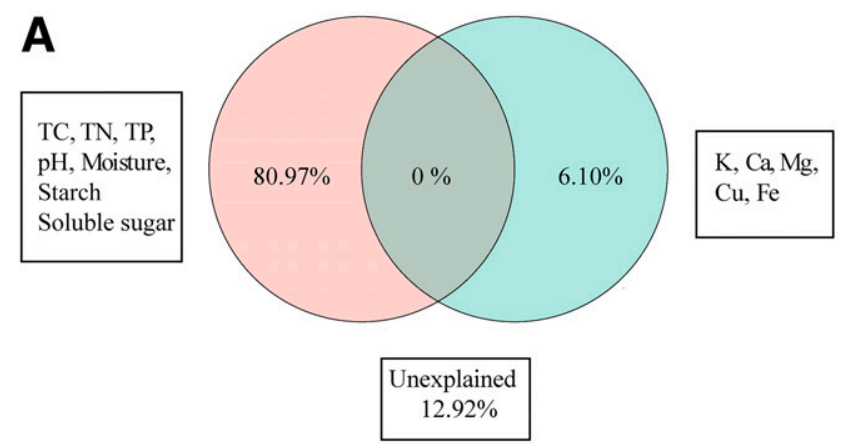

Bacteria

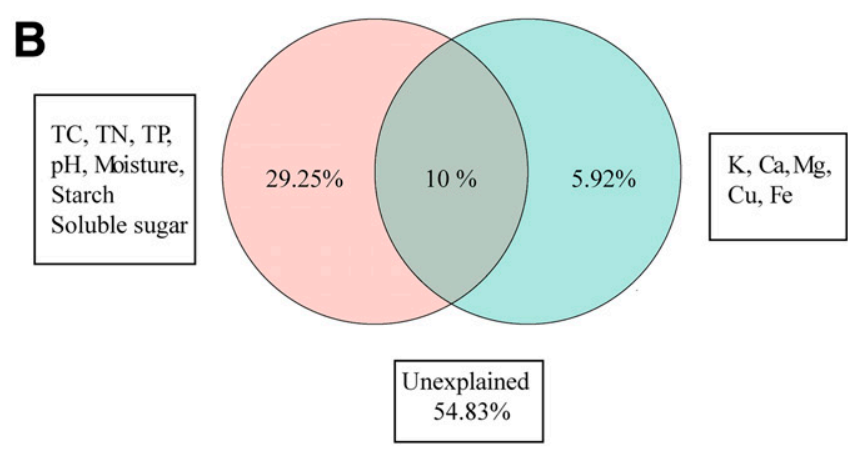

Fungi

Fig. 5. Variation partition analysis based on $\mathbf{A}$, the phyllosphere bacterial and $\mathbf{B}$, fungal community structure and leaves physicochemical variables. 
species Gemmata obscuriglobus ( $>97 \%$ similarity) (Supplementary Table S3). Interestingly, the phytoestrogens in female plants can induce the steroid transcription to microorganisms (Maier et al. 1995), which might select the Gemmata spp. in females. Besides, some rare genera $(<0.1 \%)$ were only present in females or males, such as genera Rhodococcus, Brevundimonas, and Chitinophaga, which are all found to have a potential role in organic compound metabolism (Martínková et al. 2009). Recent finding also proposed that microbial taxa with low relative abundance could have an overproportional role in biological multifunctionality and be crucial to the sustainable provision of ecosystem functions (Jousset et al. 2017). These host-specific microbes could lead to the functional divergence of female and male phyllosphere microbial communities. The individual species and rare microbial taxa have attracted welldeserved attentions (Chen et al. 2020). Therefore, the sexbiased colonization of microbes in females or males and their relationship with the division of ecological functions warrant further studies with greater details.

The phyllosphere fungal communities were dominated by members of phyla Ascomycota and Basidiomycota both in females and males, which were also found in other tree species (Davey et al. 2012; Jumpponen and Jones 2009; Kembel and Mueller 2014). Some fungal taxa were found to be preferentially enriched in females or males, respectively. A significant higher ascomycota relative abundance was observed in females than in males. Most genera of phylum Ascomycota can produce metabolites that can protect hosts from fungal pathogens (Rodriguez et al. 2009; Schulz et al. 1999). Higher concentrations of phenolic and fungal metabolites in females than in males were previously observed (Cepeda-Cornejo and Dirzo 2010; Cornelissen and Stiling 2005). The metabolites produced by fungi, such as alkaloids, and phenolic acids, in turn, have been shown to affect the growth of phyllosphere fungi (Grayer and Harborne 1994; Rauha et al. 2000), which could result in the enrichment of ascomycota in females. Besides, levels of the genera Aureobasidium and Phoma belonging to phylum Ascomycota were markedly higher in females than in males. Their closest isolates Aureobasidium pullulans and Phoma spp. have a key functional role in resisting pathogenic microorganisms (Vacher et al. 2016; Zhang et al. 2014a) and promoting plant growth (Wang et al. 2012) (Supplementary Table S3). In contrast, the relative abundance of basidiomycota was much higher in males than in females. Previous studies showed that the abundance of basidiomycota increased with the course of leaf senescence (Kembel and Mueller 2014; Osono 2006; Voříšková and Baldrian 2013). Moreover, our previous studies reported that male $P$. cathayana have a faster leaf senescence rate than females (Xu et al. 2008b; Zhao et al. 2009), which could explain the enrichment of basidiomycota in males. In addition, phyllosphere fungi have the ability to utilize various organic compounds and participate in leaf litter decomposition (Osono 2006). Members of the unique genus Pringsheimia in females possess the capacity to decompose lignin and leaf litter (Fillat et al. 2017; Voř́šková and Baldrian 2013), indicating different decomposition rate of leaves might occur in female and male $P$. cathayana. This result might also be closely related with the sampling time, further studies should consider the variations among the seasons. In addition, some fungi are not commonly present in the phyllosphere environment, such as Suillus spp. Members of the significant enriched genus Suillus in males are common ectomycorrhizal fungi colonizing the roots of plants (Kurth et al. 2013). Members of genus Suillus are common ectomycorrhizal associates of conifers in temperate region, mostly with members of family Pinaceae (Sarwar 2014; Wu et al. 2000). Recent studies showed that Suillus spp. can be detected in many other environments by using molecular sequencing analysis (Sarwar et al. 2015; Zhou et al. 2008). For example, the Suillus spp. can survive in the leaf litter of many tree types, such as genera Abies, Cedrus, Pinus, Populus, and Quercus (Sarwar 2014). Although Suillus spp. are common root ectomycorrhizal fungi, Suillus spp. were also found in beech leaf litter (Colpaert and Laere 1996). Some fungi, like Phoma spp., can rapidly emerge and sporulate on leaves during tree senescence (Weber et al. 2004). The detected Suillus species here could be due to spore deposition on the leaves, which provides a physical and chemical environment suitable for fungal growth and reproduction (Rodriguez et al. 2009). Although previous studies reported that Suillus spp. preferentially colonized in a nitrogen-limited oligotrophic environment (Lilleskov et al. 2001), how the physicochemical properties of male Populus cathayana phyllosphere environment select the Suillus species warrants further study. Furthermore, the detected Suillus spp. also imply that the detected microbial diversity might not only contain living and growing microorganisms but also include spores or sequenced 16S rRNA gene from extracellular DNA or dead cells (Blagodatskaya and Kuzyakov 2013). The identification of living and active microorganisms from the total sequenced communities on the female and male leaves should be taken into consideration in further studies.

The main nonmetal nutrients, such as $\mathrm{C}, \mathrm{N}, \mathrm{P}$, or compound (sugar, starch), were the most important contributors to variance of bacterial communities between females and males with $80.97 \%$ of the variation being explained. This observation was consistent with previous studies showing that phyllosphere bacteria communities are primarily shaped by carbon-limited and secondarily nitrogen-limited conditions (Delmotte et al. 2009; Hunter et al. 2010; Kembel et al. 2014; Wilson and Lindow 1994). In contrast, these nonmetal nutrients only contributed $29.25 \%$ of the total variations in fungal communities of females and males. This result suggested that future fungal community ecology should be explored in terms of more explanatory deterministic physicochemical factors and other potential stochastic factors (Chen et al. 2019). Besides, mineral contents contributed to the variations between females and males in the microbial communities. For instance, $\mathrm{Mg}$ and $\mathrm{Fe}$ content showed important roles in shaping fungal communities (Supplementary Fig. S6B). These results were consistent with results of previous studies showing that fungal community structures significantly correlated with mineral content (such as $\mathrm{K}, \mathrm{Al}, \mathrm{Fe}, \mathrm{Zn}$ ) of leaves (Kembel and Mueller 2014; MartínGarcía et al. 2011). $\mathrm{Mg}$ and $\mathrm{Fe}$ are involved in numerous physiological and biochemical processes in plants, including photosynthesis, enzyme activation, synthesis of nucleic acids and proteins, or nitrogen fixation (Chen et al. 2018; Graziano et al. 2002). $\mathrm{Mg}$ and Fe could affect the microbial colonization by participating physiological metabolism of plants. It was found that phyllosphere fungi can acquire $\mathrm{Mg}$ and $\mathrm{Fe}$ from their host plants (Wyszkowska and Wyszkowska 2002; Johnson 2008).

In summary, although the dominant bacterial and fungal taxa were of no significant difference between the female and male phyllosphere microbiota, there were some taxa discriminately inhabiting in females and males. Further verification studies regarding the differentiation of microbial community compositions and functions in dioecious plant is therefore of importance for revealing the evolutionary differences between females and males. Here, we propose four potential verification experiments (Supplementary Fig. S8). i) Metatranscriptomics analysis of microbial communities could be applied to detect all the genes expressed under the female and male phyllosphere environment and not only present in the samples (Moran et al. 2013). ii) Synthetic microbial community-based experiments by inoculating the synthetic community onto leaves could be 
performed to explore whether the difference microniche or microhabitat of the female and male phyllosphere environment influence the microbial communities (Xin et al. 2016). iii) Pot experiments under given conditions (such as drought, UV light, nutrient deficiency) could be established. The experiment could further verify the role of microbial communities in stress resistance of female and male $P$. cathayana by monitoring the growth of plants and dynamic change of phyllosphere microbial communities (Methe et al. 2020). iv) Active bacteria groups responsible for specific biogeochemical cycle in female and male phyllosphere environments could be traced using the DNA-stable isotope probing technique (Neufeld et al. 2007). The present study is a good start for the following verification experiments and provides typical data for microbial sexual discrimination in dioecious plants.

\section{Conclusion.}

Taken together, the results of this study underscore the role of sex selection in driving variations in the female and male phyllosphere microbial communities of $P$. cathayana. Though there were no significant differences between the females and males in the alpha diversity indexes, the microbial composition results clearly demonstrated that some microbes discriminately inhabited on females or males. These bacterial and fungal genera appeared to have special ecological function, which could be reflected in the different physiological response to environmental changes in dioecious plants. The different leaf physiochemical properties contributed differently to the variations of microbial community structure between females and males. Our results will improve our understanding of the sex discrimination of microorganism in the dioecious $P$. cathayana.

\section{MATERIALS AND METHODS}

\section{Site description and leaf sampling.}

The sampling site is located in the Xijin Valley of the Xiaowutai Mountain Nature Reserve in Hebei, China (Supplementary Fig. S9). This area is characterized by a warmtemperate continental monsoon climate with a mean annual precipitation of $528 \mathrm{~mm}$ and a mean annual temperature of $3.5^{\circ} \mathrm{C}$. The major soil type is alfisol. The forest vegetation is dominated by the genera Acer, Cerasus, Betula, Corylus, Populus, Quercus, Ulmus, or Tilia. The pure P. cathayana natural secondary forest distributes in the deciduous broad-leaf forest zone $(1,400$ to $1,800 \mathrm{~m}$ above sea level).

Leaves of $P$. cathayana were randomly collected from eight females and eight males between 1,300 and 1,400 $\mathrm{m}$ above sea level, in riparian and valley habitats, in September 2017. The selected trees were healthy, similar in habitat, full-grown with similar canopy sizes, more than 30 years old, and approximately 20 to $25 \mathrm{~m}$ tall. The trees were approximately $200 \mathrm{~m}$ away from each other. The sex of the trees was determined by observing the inflorescence during the beginning of the flowering season (the middle of April 2012). The sex of the trees was double identified by their leaf morphological characters. The morphologic characters of male and female leaves are different. The leaves of females are ovate with entire margin and apical acuminate, whereas the leaves of males are long elliptical with undulate margin and apical acuminate (Xu 2008) (Supplementary Fig. S10). Leaves from each tree were randomly obtained from three branches at the same height. The tree branches were chosen on the basis of their orientation (north, southeast, and southwest) to avoid the influence of lighting conditions in different directions. Healthy and similarly sized leaves were collected (50 to $100 \mathrm{~g}$ ) with sterile gloves and were transferred to sterile plastic bags. All the leaves were transported to the laboratory in a cooler and were then kept at $-20^{\circ} \mathrm{C}$ for further analysis.

\section{Sample physicochemical analysis.}

Fresh leaves $(0.5 \mathrm{~g})$ were chopped and ground into a homogenate, and deionized water $(30 \mathrm{ml})$ was added into the homogenate. After ultrasonic vibration filtration for $2 \mathrm{~h}$, the $\mathrm{pH}$ value was determined by a $\mathrm{pH}$ meter (Mettler-Toledo Instruments Co., Ltd.). Leaf samples were oven-dried at $70^{\circ} \mathrm{C}$ for $48 \mathrm{~h}$ and were then weighed. The dried leaves were measured to calculate the moisture content, were ground to a fine powder, and were passed through a 100-mesh screen. The TC was measured on a TOC analyzer (Elementar-TOC \& Water Analysis) by the rapid dichromate oxidation technique (Nelson et al. 1996). The concentrations of TN and TP were determined using an Auto Discrete Analyzer CleverChem 200+ (DechemTech). The content of mineral elements ( $\mathrm{K}, \mathrm{Ca}, \mathrm{Mg}, \mathrm{Cu}$, and $\mathrm{Fe})$ was determined using the flame atomic absorption method, using an atomic absorption spectrophotometer (AA-7000; Shimadzu). Fine leaf powder $(20 \mathrm{mg})$ in $4 \mathrm{ml}$ of $80 \%$ (vol/vol) ethanol was placed in a water bath at $80^{\circ} \mathrm{C}$ for $30 \mathrm{~min}$, followed by centrifugation at $5,000 \times g$ for $5 \mathrm{~min}$. Samples were then extracted three times, and the supernatants were pooled together for sugar analysis. The residues remaining in the centrifuge tubes were stored wet at $-20^{\circ} \mathrm{C}$ for starch analysis. After the addition of $2 \mathrm{ml}$ of distilled water, the tubes were placed in a boiling water bath for $15 \mathrm{~min}$ and $1 \mathrm{ml}$ of $9.2 \mathrm{M}$ perchloric acid and $1 \mathrm{ml}$ of distilled water was added after coolingand the mixture was shaken for $15 \mathrm{~min}$. The supernatants were then collected after centrifugation at $5,000 \times g$ for $5 \mathrm{~min}$. The residues were reextracted and the supernatants were combined for starch analysis. Total soluble sugars and starch were both determined colorimetrically at $625 \mathrm{~nm}$ by the phenol-sulfuric acid method, using glucose as the standard (DuBois et al. 1956). All samples were analyzed in triplicate.

\section{Leaf DNA extraction and real-time quantitative PCR.}

Microbial cells were collected from the phyllosphere as previously described (Kembel et al. 2014). In brief, microbial cells were collected from leaf surfaces by agitating leaves $(10 \mathrm{~g})$ for $5 \mathrm{~min}$ in $100 \mathrm{ml}$ of 1:50 diluted washing solution (1 M Tris $\cdot \mathrm{HCl}, 0.5 \mathrm{M}$ Na EDTA, and $1.2 \%$ cetyltrimethylammonium bromide [Kadivar and Stapleton 2003]). The washing solution was centrifuged at 4,000 $\times g$ for $20 \mathrm{~min}$ and the supernatant was removed by pipetting. Cells were resuspended in $500 \mu \mathrm{l}$ of the Fast DNA SPIN bead solution, and the total DNA was extracted using the Fast DNA spin kit (Qbiogene) according to manufacturer protocol. The quality and quantity of extracted DNA were determined using a NanoDrop spectrophotometer (NanoDrop Technologies). The DNA samples were stored at $-20^{\circ} \mathrm{C}$ for later use.

\section{Illumina MiSeq sequencing of 16S rRNA and ITS1 gene amplicons.}

Illumina MiSeq sequencing was employed to investigate the diversity of phyllosphere bacterial and fungal communities in female and male $P$. cathayana leaves. The primer pairs 515/907 and ITS5F/ITS1R were used for the amplification of the bacterial 16S rRNA gene and fungal ITS1 gene, respectively. The PCR primers and conditions are listed in Supplementary Table S4. Detailed sequencing analysis for sequencing was performed using the quantitative insights into microbial ecology (QIIME) 2 software package (v1.8.0) (Caporaso et al. 2010) as described previously (Wang et al. 2018). The sequences of chloroplastic and mitochondrial origin were removed. Sequences shorter than $150 \mathrm{bp}$, containing N6 ambiguous bases or a homopolymer longer than $6 \mathrm{bp}$, having one or more mismatching bases in the 
primer or barcode, or showing a quality score below 20 were eliminated from further analysis. The data were denoised using the AmpliconNoise program (Quince et al. 2011). Finally, highquality sequences were clustered into OTUs based on $97 \%$ sequence similarity with UCLUST (Edgar 2010). Nonparametric calculations of minimum community richness, including Chao 1 and ACE (Chao 1984; Chao and Lee 1992) were performed at a genetic distance of 0.03 . The Shannon and Simpson indexes were calculated to compare species diversity and evenness as described previously (Schloss et al. 2009). Besides, we defined the genus relative abundance threshold as $0.1 \%$ for rare genera and $>0.1 \%$ for abundance genera.

The physicochemical properties of the leaves were compared with multiple-sample comparisons using one-way analysis of variance to check for quantitative variance between female and male samples. SPSS version 20.0 was used for statistical analysis (SPSS Inc.). Differences were considered significant at the $P<0.05$ level. Compositional dissimilarity of phyllosphere microbiota structure between females and males were analyzed by a NMDS plots based on Bray-Curtis distance of the $R$ vegan package (Anderson 2001). The adonis analysis test was used to compare the variations between intraplant (individual trees) and interplant (females vs. males), using a permutational multivariate analysis of variance. Analyses of variance were performed with the adonis function of the $R$ vegan package by using 999 permutations (Anderson 2001). Correlations between leaf physicochemical properties and phyllosphere bacterial and fungal community compositions were calculated by RDA. VPA was used to quantitatively assess the individual and common interpretation of two or more groups (groups 2 to 4) of environmental factor variables to microbial community differences. The RDA and VPA were conducted using $\mathrm{R}$ 3.3.1 with the vegan package. Bacterial and fungal community comparisons at the phylum and genus levels were performed using Metastats (White et al. 2009). Bar charts were generated by OriginPro 81 .

\section{ACKNOWLEDGMENTS}

We thank H. Li and Z. Meng for their assistance in chemical analysis.

\section{LITERATURE CITED}

Anderson, M. J. 2001. A new method for non-parametric multivariate analysis of variance. Austral Ecol. 26:32-46.

Bailey, M. J., Lilley, A. K., Timmswilson, T. M., and Spencerphillips, P. T. N. 2006. Microbial Ecology of Aerial Plant Surfaces. CABI, Wallingford, U.K.

Balint-Kurti, P., Simmons, S. J., Blum, J. E., Ballaré, C. L., and Stapleton, A. E. 2010. Maize leaf epiphytic bacteria diversity patterns are genetically correlated with resistance to fungal pathogen infection. Mol. Plant-Microbe Interact 23:473-484.

Bengtsson, M. M., and Øvreås, L. 2010. Planctomycetes dominate biofilms on surfaces of the kelp Laminaria hyperborea. BMC Microbiol. 10:261.

Blagodatskaya, E., and Kuzyakov, Y. 2013. Active microorganisms in soil: Critical review of estimation criteria and approaches. Soil Biol. Biochem. 67:192-211.

Boerner, R. E. J. 1984. Foliar nutrient dynamics and nutrient use efficiency of four deciduous tree species in relation to site fertility. J. Appl. Ecol. 21:1029-1040.

Bulgarelli, D., Schlaeppi, K., Spaepen, S., Ver Loren van Themaat, E., and Schulze-Lefert, P. 2013. Structure and functions of the bacterial microbiota of plants. Annu. Rev. Plant Biol. 64:807-838.

Caporaso, J. G., Kuczynski, J., Stombaugh, J., Bittinger, K., Bushman, F. D., Costello, E. K., Fierer, N., Peña, A. G., Goodrich, J. K., Gordon, J. I., Huttley, G. A., Kelley, S. T., Knights, D., Koenig, J. E., Ley, R. E., Lozupone, C. A., McDonald, D., Muegge, B. D., Pirrung, M., Reeder, J., Sevinsky, J. R., Turnbaugh, P. J., Walters, W. A., Widmann, J., Yatsunenko, T., Zaneveld, J., and Knight, R. 2010. QIIME allows analysis of high-throughput community sequencing data. Nat. Methods 7:335-336.
Cepeda-Cornejo, V., and Dirzo, R. 2010. Sex-related differences in reproductive allocation, growth, defense and herbivory in three dioecious neotropical palms. PLoS One 5:e9824.

Chao, A. 1984. Nonparametric estimation of the number of classes in a population. Scand. J. Stat. 11:265-270.

Chao, A., and Lee, S. M. 1992. Estimating the number of classes via sample coverage. J. Am. Stat. Assoc. 87:210-217.

Chen, L., Dong, T., and Duan, B. 2014. Sex-specific carbon and nitrogen partitioning under $\mathrm{N}$ deposition in Populus cathayana. Trees 28:793-806.

Chen, L., Zhang, S., Zhao, H., Korpelainen, H., and Li, C. 2010. Sex-related adaptive responses to interaction of drought and salinity in Populus yunnanensis. Plant Cell Environ. 33:1767-1778.

Chen, Q. L., Ding, J., Zhu, D., Hu, H. W., Delgado, B. M., Ma, Y. B., He, J. Z., and Zhu, Y. G. 2020. Rare microbial taxa as the major drivers of ecosystem multifunctionality in long-term fertilized soils. Soil Biol. Biochem. 141:107686.

Chen, W., Ren, K., Isabwe, A., Chen, H., Liu, M., and Yang, J. 2019. Stochastic processes shape microeukaryotic community assembly in a subtropical river across wet and dry seasons. Microbiome 7:148.

Chen, Z. C., Peng, W. T., Li, J., and Liao, H. 2018. Functional dissection and transport mechanism of magnesium in plants. Semin. Cell Dev. Biol. 74:142-152.

Cipollini, M. L., and Whigham, D. F. 1994. Sexual dimorphism and cost of reproduction in the dioecious shrub Lindera benzoin (Lauraceae). Am. J. Bot. 81:65-75.

Colpaert, J. V., and Laere, A. 1996. A comparison of the extracellular enzyme activities of two ectomycorrhizal and a leaf-saprotrophic basidiomycete colonizing beech leaf litter. New Phytol. 134:133-141.

Cordier, T., Robin, C., Capdevielle, X., Desprez, L. M. L., and Vacher, C. 2012a. Spatial variability of phyllosphere fungal assemblages: Genetic distance predominates over geographic distance in a European beech stand (Fagus sylvatica). Fungal Ecol. 5:509-520.

Cornelissen, T., and Stiling, P. 2005. Sex-biased herbivory: A meta-analysis of the effects of gender on plant-herbivore interactions. Oikos 111: 488-500.

Davey, M. L., Heegaard, E., Halvorsen, R., Ohlson, M., and Kauserud, H. 2012. Seasonal trends in the biomass and structure of bryophyteassociated fungal communities explored by 454 pyrosequencing. New Phytol. 195:844-856

Delmotte, N., Knief, C., Chaffron, S., Innerebner, G., Roschitzki, B., Schlapbach, R., von Mering, C., and Vorholt, J. A. 2009. Community proteogenomics reveals insights into the physiology of phyllosphere bacteria. Proc. Natl. Acad. Sci. U.S.A. 106:16428-16433.

DuBois, G. K., Hamilton, J. K., Rebers, P. A., and Smith, F. 1956. Colorimetric method for determination of sugars and related substances. Anal. Chem. 28:350-356.

Edgar, R. C. 2010. Search and clustering orders of magnitude faster than BLAST. Bioinformatics 26:2460-2461.

Fierer, N. 2017. Embracing the unknown: Disentangling the complexities of the soil microbiome. Nat. Rev. Microbiol. 15:579-590.

Fillat, U., Raquel, M. S., Macaya, D., Juan, A. M., and María, E. E. 2017. Potential of lignin-degrading endophytic fungi on lignocellulosic biorefineries. Endophyte, Pages 261-281 in: Endophyte Vol II: Crop Productivity and Protection. Sustainable Development and Biodiversity, Vol. 16. D. Maheshwari and K. Annapurna, eds. Springer, Cham, Switzerland.

Fürnkranz, M., Wanek, W., Richter, A., Abell, G., Rasche, F., and Sessitsch, A. 2008. Nitrogen fixation by phyllosphere bacteria associated with higher plants and their colonizing epiphytes of a tropical lowland rainforest of Costa Rica. ISME J. 2:561-570.

Gomes, T., Pereira, J. A., Benhadi, J., Lino-Neto, T., and Baptista, P. 2018. Endophytic and epiphytic phyllosphere fungal communities are shaped by different environmental factors in a Mediterranean ecosystem. Microb. Ecol. 76:668-679.

Grayer, R., and Harborne, J. B. 1994. A survey of antifungal compounds from higher plants. Phytochemistry 37:19-42.

Graziano, M., Beligni, M. V., and Lamattina, L. 2002. Nitric oxide improves internal iron availability in plants. Plant Physiol. 130: 1852-1859

Hunter, P. J., Hand, P., Pink, D., Whipps, J. M., and Bending, G. D. 2010. Both leaf properties and microbe-microbe interactions influence withinspecies variation in bacterial population diversity and structure in the lettuce (Lactuca species) phyllosphere. Appl. Environ. Microbiol. 76: 8117-8125

Innerebner, G., Knief, C., and Vorholt, J. A. 2011. Protection of Arabidopsis thaliana against leaf-pathogenic Pseudomonas syringae by Sphingomonas strains in a controlled model system. Appl. Environ. Microbiol. 77 3202-3210. 
Jiang, Z. K., Tuo, L., Huang, D. L., Osterman, I. A., Tyurin, A. P., Liu, S. W., Lukyanov, D. A., Sergiev, P. V., Dontsova, O. A., Korshun, V. A., Li, F. N., and Sun, C. H. 2018. Diversity, novelty, and Antimicrobial activity of endophytic actinobacteria from mangrove plants In Beilun Estuary National Nature Reserve of Guangxi, China. Front. Microbiol. 9: 868

Johnson, L. 2008. Iron and siderophores in fungal-host interactions. Mycol. Res. 112:170-183.

Joo, E. S., Kim, E. B., Jeon, S. H., Srinivasan, S., and Kim, M. K. 2017. Spirosoma swuense sp. nov., isolated from wet soil. Int. J. Syst. Evol. Microbiol. 67:532-536.

Jousset, A., Bienhold, C., Chatzinotas, A., Gallien, L., Gobet, A., Kurm, V., Küsel, K., Rillig, M. C., Rivett, D. W., Salles, J. F., van der Heijden, M. G., Youssef, N. H., Zhang, X., Wei, Z., and Hol, W. H. 2017. Where less may be more: How the rare biosphere pulls ecosystems strings. ISME J. 11:853-862.

Jumpponen, A., and Jones, K. L. 2009. Massively parallel 454 sequencing indicates hyperdiverse fungal communities in temperate Quercus macrocarpa phyllosphere. New Phytol. 184:438-448.

Kaczmarczyk, A., Campagne, S., Danza, F., Metzger, L. C., Vorholt, J. A., and Francez-Charlot, A. 2011. Role of Sphingomonas sp. strain Fr1 PhyR-NepR- $\sigma$ EcfG cascade in general stress response and identification of a negative regulator of PhyR. J. Bacteriol. 193:6629-6638.

Kadivar, H., and Stapleton, A. E. 2003. Ultraviolet radiation alters maize phyllosphere bacterial diversity. Microb. Ecol. 45:353-361.

Kembel, S. W., and Mueller, R. C. 2014. Plant traits and taxonomy drive host associations in tropical phyllosphere fungal communities. Botany 92:303-311.

Kembel, S. W., O’Connor, T. K., Arnold, H. K., Hubbell, S. P., Wright, S. J., and Green, J. L. 2014. Relationships between phyllosphere bacterial communities and plant functional traits in a neotropical forest. Proc. Natl. Acad. Sci. U.S.A. 111:13715-13720.

Kim, M., Singh, D., Lai-Hoe, A., Go, R., Abdul Rahim, R., Ainuddin, A. N., Chun, J., and Adams, J. M. 2012. Distinctive phyllosphere bacterial communities in tropical trees. Microb. Ecol. 63:674-681.

Kurth, F., Zeitler, K., Feldhahn, L., Neu, T. R., Weber, T., Krištůfek, V., Wubet, T., Herrmann, S., Buscot, F., and Tarkka, M. T. 2013. Detection and quantification of a mycorrhization helper bacterium and a mycorrhizal fungus in plant-soil microcosms at different levels of complexity. BMC Microbiol. 13:205.

Lee, J. J., Kang, M. S., Joo, E. S., Kim, M. K., Im, W. T., Jung, H. Y., and Srinivasan, S. 2015. Spirosoma montaniterrae sp. nov., an ultraviolet and gamma radiation-resistant bacterium isolated from mountain soil. J. Microbiol. 53:429-434.

Lee, J. J., Srinivasan, S., Lim, S., Joe, M., Im, S., Bae, S. I., Park, K. R., Han, J. H., Park, S. H., Joo, B. M., Park, S. J., and Kim, M. K. 2014. Spirosoma radiotolerans $\mathrm{sp}$. nov., a gamma-radiation-resistant bacterium isolated from gamma ray-irradiated soil. Curr. Microbiol. 69:286-291.

Leigh, A., Cosgrove, M., and Nicotra, A. 2006. Reproductive allocation in a gender dimorphic shrub: Anomalous female investment in Gynatrix pulchella? J. Ecol. 94:1261-1271.

Leveau, J. H., and Lindow, S. E. 2001. Appetite of an epiphyte: Quantitative monitoring of bacterial sugar consumption in the phyllosphere. Proc. Natl. Acad. Sci. U.S.A. 98:3446-3453.

Lilleskov, E., Fahey, T., and Lovett, G. 2001. Ectomycorrhizal fungal aboveground community change over an atmospheric nitrogen deposition gradient. Ecol. Appl. 11:397-410.

Lindow, S. E., and Brandl, M. T. 2003. Microbiology of the phyllosphere. Appl. Environ. Microbiol. 69:1875-1883.

Lindow, S. E., and Leveau, J. H. J. 2002. Phyllosphere microbiology. Curr. Opin. Biotechnol. 13:238-243.

Liu, X. 2003. Study on character of Populus cothayna male tree and its genetic dominance. Qinghai Agriculture and Forestry Technology 3: 22-23.

Lonhienne, T. G. A., Sagulenko, E., Webb, R. I., Lee, K. C., Franke, J., Devos, D. P., Nouwens, A., Carroll, B. J., and Fuerst, J. A. 2010. Endocytosis-like protein uptake in the bacterium Gemmata obscuriglobus. Proc. Natl. Acad. Sci. U.S.A. 107:12883-12888.

Maier, C. G.-A., Chapman, K. D., and Smith, D. W. 1995. Differential estrogenic activities of male and female plant extracts from two dioecious species. Plant Sci. 109:31-43.

Mariano, R. L. R., and McCarter, S. M. 1993. Epiphytic survival of Pseudomonas viridiflava on tomato and selected weed species. Microb. Ecol. 26:47-58.

Martín-García, G. J., Espiga, E., Pando, V., and Diez, J.2011. Factors influencing endophytic communities in poplar plantations. Silva Fenn. 45:169-180.
Martínková, L., Uhnáková, B., Pátek, M., Nesvera, J., and Kren, V. 2009. Biodegradation potential of the genus Rhodococcus. Environ. Int. 35: 162-177.

Methe, B. A., Hiltbrand, D., Roach, J., Xu, W., Gordon, S. G., Goodner, B. W., and Stapleton, A. E. 2020. Functional genes that distinguish maize phyllosphere metagenomes in drought and well-watered conditions. BioRxiv.

Mew, T. W. 1984. Scanning electron microscopy of virulent and avirulent strains of Xanthomonas campestris pv. oryzae on rice leaves. Phytopathology 74:635-641.

Moran, M. A., Satinsky, B., Gifford, S. M., Luo, H., Rivers, A., Chan, L. K., Meng, J., Durham, B. P., Shen, C., Varaljay, V. A., Smith, C. B., Yager, P. L., and Hopkinson, B. M. 2013. Sizing up metatranscriptomics. ISME J. 7:237-243.

Nelson, D. W., Sommers, L. E., Sparks, D. L., Page, A. L., Helmke, P. A. Loeppert, R. H., Soltanpour, P. N., Tabatabai, M. A., Johnston, C. T., and Sumner, M. E. 1996. Total carbon, organic carbon, and organic matter. Methods Soil Anal. 9:961-1010.

Neufeld, J. D., Schäfer, H., Cox, M. J., Boden, R., McDonald, I. R., and Murrell, J. C. 2007. Stable-isotope probing implicates Methylophaga spp and novel Gammaproteobacteria in marine methanol and methylamine metabolism. ISME J. 1:480-491.

Osono, T. 2006. Role of phyllosphere fungi of forest trees in the development of decomposer fungal communities and decomposition processes of leaf litter. Can. J. Microbiol. 52:701-716.

Pearson, A., Budin, M., and Brocks, J. J. 2003. Phylogenetic and biochemical evidence for sterol synthesis in the bacterium Gemmata obscuriglobus. Proc. Natl. Acad. Sci. U.S.A. 100:15352-15357.

Quince, C., Lanzen, A., Davenport, R. J., and Turnbaugh, P. J. 2011. Removing noise from pyrosequenced amplicons. BMC Bioinformatics $12: 38$.

Rastogi, G., Coaker, G. L., and Leveau, J. H. 2013. New insights into the structure and function of phyllosphere microbiota through highthroughput molecular approaches. FEMS Microbiol. Lett. 348:1-10.

Rauha, J. P., Remes, S., Heinonen, M., Hopia, A., Kähkönen, M., Kujala, T., Pihlaja, K., Vuorela, H., and Vuorela, P. 2000. Antimicrobial effects of Finnish plant extracts containing flavonoids and other phenolic compounds. Int. J. Food Microbiol. 56:3-12.

Redford, A. J., Bowers, R. M., Knight, R., Linhart, Y., and Fierer, N. 2010. The ecology of the phyllosphere: Geographic and phylogenetic variability in the distribution of bacteria on tree leaves. Environ. Microbiol. 12:2885-2893.

Redford, A. J., and Fierer, N. 2009. Bacterial succession on the leaf surface: A novel system for studying successional dynamics. Microb. Ecol. 58 : 189-198.

Reed, S. C., Townsend, A. R., Cleveland, C. C., and Nemergut, D. R. 2010. Microbial community shifts influence patterns in tropical forest nitrogen fixation. Oecologia 164:521-531.

Ren, G., Zhang, H., Lin, X., Zhu, J., and Jia, Z. 2014. Response of phyllosphere bacterial communities to elevated $\mathrm{CO} 2$ during rice growing season. Appl. Microbiol. Biotechnol. 98:9459-9471.

Renner, S. S., and Ricklefs, R. E. 1995. Dioecy and its correlates in the flowering plants. Am. J. Bot. 82:596-606.

Rodriguez, R. J., White, J. F., Jr., Arnold, A. E., and Redman, R. S. 2009. Fungal endophytes: Diversity and functional roles. New Phytol. 182: 314-330.

Sarwar, S. 2014. Diversity and phylogeny of genus Suillus (Suillaceae, Boletales) from coniferous forests of Pakistan (Asia). Int. J. Agric. Biol. 16:489-497.

Sarwar, S., Saba, M., Khalid, A. N., and Dentinger, B. M. 2015. Suillus marginielevatus, a new species and $S$. triacicularis, a new record from Western Himalaya, Pakistan. Phytotaxa 203:169-177.

Schloss, P. D., Westcott, S. L., Ryabin, T., Hall, J. R., Hartmann, M. Hollister, E. B., Lesniewski, R. A., Oakley, B. B., Parks, D. H., Robinson, C. J., Sahl, J. W., Stres, B., Thallinger, G. G., Van Horn, D. J., and Weber, C. F. 2009. Introducing mothur: Open-source, platformindependent, community-supported software for describing and comparing microbial communities. Appl. Environ. Microbiol. 75:7537-7541.

Schulz, B., Römmert, A. K., Dammann, U., Aust, H. J., and Strack, D. 1999. The endophyte-host interaction: A balanced antagonism? Mycol. Res. 103:1275-1283.

Selvakumar, G., Panneerselvam, P., and Ganeshamurthy, A. N. 2014 Diversity utility and potential of Actinobacteria in the agro-ecosystem. Bacterial Divers. Sustain. Agric. 1:23-40.

Stone, B. W. G., Weingarten, E. A., and Jackson, C. R. 2018. The role of the phyllosphere microbiome in plant health and function. Annu. Plant Rev. 1:533-556. 
Vacher, C., Hampe, A., Porté, A. J., Sauer, U., Compant, S., and Morris, C. E. 2016. The phyllosphere: Microbial jungle at the plant-climate interface. Annu. Rev. Ecol. Evol. Syst. 47:1-24.

Viret, O., and Petrini, O. 1994. Colonization of beech leaves (Fagus sylvatica) by the endophyte Discula umbrinella (teleomorph: Apiognomonia errabunda). Mycol. Res. 98:423-432.

Vorholt, J. A. 2012. Microbial life in the phyllosphere. Nat. Rev. Microbiol. 10:828-840.

Vořŕšková, J., and Baldrian, P. 2013. Fungal community on decomposing leaf litter undergoes rapid successional changes. ISME J. 7:477-486.

Wagner, M., and Horn, M. 2006. The Planctomycetes, Verrucomicrobia, Chlamydiae and sister phyla comprise a superphylum with biotechnological and medical relevance. Curr. Opin. Biotechnol. 17:241-249.

Wang, B. X., Liao, Y. M., Huang, Y. Y., Jiang, X. M., and Xiao, X. 2010. Sex-specific heterogeneity in stomatal distribution and gas exchange of male and female Populus cathayana leaves. Acta Bot. Yunnanica 31: 439-446.

Wang, L., Zhang, J., Li, H., Yang, H., Peng, C., Peng, Z., and Lu, L. 2018. Shift in the microbial community composition of surface water and sediment along an urban river. Sci. Total Environ. 627:600-612.

Wang, L. W., Xu, B. G., Wang, J. Y., Su, Z. Z., Lin, F. C., Zhang, C. L., and Kubicek, C. P. 2012. Bioactive metabolites from Phoma species, an endophytic fungus from the Chinese medicinal plant Arisaema erubescens. Appl. Microbiol. Biotechnol. 93:1231-1239.

Weber, R. W. S., Stenger, E., Meffert, A., and Hahn, M. 2004. Brefeldin A production by Phoma medicaginis in dead pre-colonized plant tissue: A strategy for habitat conquest? Mycol. Res. 108:662-671.

Whipps, J. M., Hand, P., Pink, D., and Bending, G. D. 2008. Phyllosphere microbiology with special reference to diversity and plant genotype. J. Appl. Microbiol. 105:1744-1755.

White, J. R., Nagarajan, N., and Pop, M. 2009. Statistical methods for detecting differentially abundant features in clinical metagenomic samples. PLOS Comput. Biol. 5:e1000352.

Wilson, M., and Lindow, S. E. 1994. Coexistence among epiphytic bacterial populations mediated through nutritional resource partitioning. Appl. Environ. Microbiol. 60:4468-4477.

Wu, Q., Tang, Y., Dong, T., Liao, Y., Li, D., He, X., and Xu, X. 2018. Additional AM fungi inoculation increase Populus cathayana intersexual competition. Front. Plant Sci. 9:607.

Wu, Q. X., Mueller, G. M., Lutzoni, F. M., Huang, Y. Q., and Guo, S. Y. 2000. Phylogenetic and biogeographic relationships of eastern Asian and eastern North American disjunct Suillus species (fungi) as inferred from nuclear ribosomal RNA ITS sequences. Mol. Phylogenet. Evol. 17: 37-47.

Wyszkowska, J., and Wyszkowska, M. 2002. Effect of cadmium and magnesium on microbiological activity in soil. Pol. J. Environ. Stud. 11: 585-591.

Xin, X. F., Nomura, K., Aung, K., Velásquez, A. C., Yao, J., Boutrot, F., Chang, J. H., Zipfel, C., and He, S. Y. 2016. Bacteria establish an aqueous living space in plants crucial for virulence. Nature 539:524-529.
Xu, X. 2008. Different ecophysiological responses between males and females of Populus cathayana Rehd. to drought stress. Chengdu Institute of Biology, the Chinese Academy of Sciences, Chengdu, China.

Xu, X., Peng, G., Wu, C., Korpelainen, H., and Li, C. 2008a. Drought inhibits photosynthetic capacity more in females than in males of Populus cathayana. Tree Physiol. 28:1751-1759.

Xu, X., Yang, F., Xiao, X., Zhang, S., Korpelainen, H., and Li, C. 2008b. Sex-specific responses of Populus cathayana to drought and elevated temperatures. Plant Cell Environ. 31:850-860.

Xu, X., Zhao, H., Zhang, X., Hänninen, H., Korpelainen, H., and Li, C. 2010. Different growth sensitivity to enhanced UV-B radiation between male and female Populus cathayana. Tree Physiol. 30:1489-1498.

Yadav, R. K., Karamanoli, K., and Vokou, D. 2005. Bacterial colonization of the phyllosphere of mediterranean perennial species as influenced by leaf structural and chemical features. Microb. Ecol. 50:185-196.

Yang, C. H., Crowley, D. E., Borneman, J., and Keen, N. T. 2001. Microbial phyllosphere populations are more complex than previously realized. Proc. Natl. Acad. Sci. U.S.A. 98:3889-3894.

Yang, Y., He, X., Xu, X., and Yang, D. 2015. Scaling relationships among twig components are affected by sex in the dioecious tree Populus cathayana. Trees 29:737-746.

Zhang, Q., Zhang, J., Yang, L., Zhang, L., Jiang, D., Chen, W., and Li, G. 2014a. Diversity and biocontrol potential of endophytic fungi in Brassica napus. Biol. Control 72:98-108.

Zhang, S., Chen, F., Peng, S., Ma, W., Korpelainen, H., and Li, C. 2010a. Comparative physiological, ultrastructural and proteomic analyses reveal sexual differences in the responses of Populus cathayana under drought stress. Proteomics 10:2661-2677.

Zhang, S., Chen, L., Duan, B., Korpelainen, H., and Li, C. 2012. Populus cathayana males exhibit more efficient protective mechanisms than females under drought stress. For. Ecol. Manage. 275:68-78.

Zhang, S., Jiang, H., Peng, S., Korpelainen, H., and Li, C. 2011. Sex-related differences in morphological, physiological, and ultrastructural responses of Populus cathayana to chilling. J. Exp. Bot. 62:675-686.

Zhang, S., Jiang, H., Zhao, H., Korpelainen, H., and Li, C. 2014b. Sexually different physiological responses of Populus cathayana to nitrogen and phosphorus deficiencies. Tree Physiol. 34:343-354.

Zhang, S., Lu, S., Xu, X., Korpelainen, H., and Li, C. 2010b. Changes in antioxidant enzyme activities and isozyme profiles in leaves of male and female Populus cathayana infected with Melampsora larici-populina. Tree Physiol. 30:116-128.

Zhao, H., Li, Y., Duan, B., Korpelainen, H., and Li, C. 2009. Sex-related adaptive responses of Populus cathayana to photoperiod transitions. Plant Cell Environ. 32:1401-1411.

Zhao, H., Xu, X., Zhang, Y., Korpelainen, H., and Li, C. 2011. Nitrogen deposition limits photosynthetic response to elevated $\mathrm{CO}_{2}$ differentially in a dioecious species. Oecologia 165:41-54.

Zhou, Z., Miwa, M., and Hogetsu, T. 2008. Polymorphism of simple sequence repeats reveals gene flow within and between ectomycorrhizal Suillus grevillei populations. New Phytol. 149:339-348. 